Journal of Mathematics and Statistics Studies

ISSN: 2709-4200

DOI: $10.32996 /$ jmss

Journal Homepage: www.al-kindipublisher.com/index.php/jmss

\title{
Inference on Reported Vehicular Fatal Accidents in Nigeria Using a Bayesian Model
}

\author{
Olalude Gbenga Adelekan 1 8D, Mbata Ahamefula Ugochukwu 8 (D. \\ ${ }^{13}$ Department of Statistics, Federal Polytechnic Ede, Osun, Nigeria \\ ${ }^{2}$ Department of Mathematics, University of Lagos, Lagos, Nigeria
}

$\triangle$ Corresponding Author: Mbata Ahamefula Ugochukwu, E-mail: mbataugochukwu@gmail.com

\begin{abstract}
ARTICLE INFORMATION
Received: April 08, 2021

Accepted: June 02, 2021

Volume: 4

Issue: 3

DOI: $10.32996 / j m s s .2021 .2 .1 .6$

\section{KEYWORDS}

Fatal Accident, Mapping, Empirical

Bayes, Poisson-Generalized

Gamma, Relative Risk

\section{ABSTRACT}

The study introduced a special case of the Poisson-Generalized Gamma empirical Bayes model to survey states in Nigeria with a higher risk of fatal accidents. Monte Carlo error and stationary dynamic trace plots were used to validate model convergence and accuracy of the posterior estimates. The main results included the disease mappings that revealed Ebonyi had the highest risk of road vehicular fatal accidents in Nigeria with a relative risk estimate of 1.4120 while Abuja had the lowest risk with a relative risk estimate 0.5711 . In terms of geopolitical region, the risk of road vehicular fatal accident is highest in South-South region with a relative risk estimate of 1.1850 while North-Central had the lowest risk with a relative risk estimate of 0.7846. The study is to aid planned government programs to ameliorate vehicular road carnage in Nigeria.
\end{abstract}

\section{Introduction}

The alarming rate of road vehicular accidents in Nigeria is becoming worrisome to individuals and government alike. According to the WHO (2018), accidents caused an estimated 1.35 million deaths worldwide. Further, as noted in the WHO (2018) report, road accident is one of the leading causes of death in the world. The risk of dying by road accident injury is highest in the African region with 26.6 traffic deaths per 100,000 people and lowest in the European region with 9.3 traffic deaths per 100,000 people. Nigeria statistics is succinctly put at 20.5 traffic deaths per 100,000 people and 615.4 traffic deaths per 100,000 motor vehicles, with a total fatality of 46,475 between 2013 and 2019 (NBS, 2019). These figures placed Nigeria among the highest in the rate of road accidents in the world and traffic deaths per inhabitants.

According to WHO (2018), the Nigeria figures are relatively very high compared with the United States' 12.4 traffic deaths per 100,000 populations, 14.2 traffic deaths per 100,000 motor vehicles, with the United Kingdom's 3.1 deaths per 100,000 people, 5.7 traffic deaths per 100,000 motor vehicles and with the China's 18.2 traffic deaths per 100,000 populations, 104.5 traffic deaths per 100,000 motor vehicles. As highlighted in NBS (2019), the vehicle population in Nigeria is put at 11,826,033, and the Nigeria's vehicle per population ratio is put at 0.06 . The road is a primary means of commuting in Nigeria. According to NBS (2019), the current vehicular density in Nigeria is put at 60 vehicles every $1 \mathrm{~km}$, which poses a major challenge to road traffic. As discussed in Uchenna et al. (2019), Afolabi and Gbadamosi (2017), Oyenuga et al. (2016), Ohakwe et al. (2011), the causes of road accidents in Nigeria are diverse but linked to road conditions, vehicle conditions and driving habits which include over-speeding, drinkdriving and overloading.

In this study, a special case of Poisson-Generalized Gamma (PGG) empirical Bayes model is proposed to investigate states in Nigeria with a higher risk of fatal accidents. The empirical Bayes (EB) model was considered appropriate because the accident data are from thirty-seven (37) independent but similar studies which EB method has the capacity to handle (Mbata et al., 2018; Okafor and Mbata, 2012). EB analysis can also remove the random variability within and across studies, usually present in data from small population counts (Böhning et al., 2000; Raudenbush and Bryk, 1985). The following scholars have also employed EB model to study accident data in terms of estimation, prediction and trend pattern; Lee et al. (2019), Soro and Wayoro (2017),

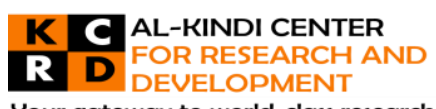

Your gateway to world-class research

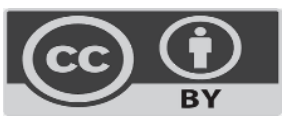

Published by Al-Kindi Center for Research and Development. Copyright (c) the author(s). This open access article is distributed under a Creative Commons Attribution (CC-BY) 4.0 license 
Fawcett et al. (2017), and Vogelesang (1997). The study was motivated because of the growing number of fatal vehicular crashes on Nigerian roads. Also, the need to identify the hotspot states towards curbing vehicular crashes on Nigerian roads. The remainder of the paper is structured as follows: the special case of PGG EB model is presented in Section 2, Section 3 deals with the data application and results, discussions of results was done in Section 4 and Section 5 highlighted the Summary and conclusion.

\section{Methodology}

The proposed EB model is a special case of Poisson-Generalized Gamma model (PGG) introduced by Mbata et al. (2018). The model is built on Bayes' Theorem and has the form of Equation (1) (Gelman et al., 2004):

$p(\tilde{\theta} \mid y, \emptyset)=\frac{l(\theta \mid y) p(\theta \mid \emptyset)}{\int_{\theta} l(\theta \mid y) p(\theta \mid \emptyset) d \theta} \propto l(\theta \mid y) p(\theta \mid \varnothing)$

Where, $\int_{\theta} l(\theta \mid y) p(\theta \mid \varnothing) d \theta$ is the unconditional marginal distribution whose inverse is the constant of proportionality $(c)$. The quantity $c$ is a normalizing constant to ensure that the posterior distribution $p(\tilde{\theta} \mid y, \emptyset)$ is a proper density. $\emptyset$ represents the hyperparameters of the prior distribution $(p(\theta \mid \varnothing))$ usually estimated from the observed data $(y)$. It implies that: (i) $p(\tilde{\theta} \mid y, \emptyset)$ are the posterior distributions of the parameters $\theta$ given $(y)$ and hyperparameters $(\varnothing)$ in the model after observing the data. (ii) $l(\theta \mid y)$ is the likelihood function of the probability distribution with respect to $\theta$, which reflects the relationship between the data and the parameter(s). (iii) $p(\theta \mid \varnothing)$ is the prior distribution of the parameter $\theta$ given the hyperparameters $(\varnothing)$, which reflects the initial information on the parameter(s). Generally, a Bayesian model consists of a likelihood distribution and a prior distribution. The inference about the parameter of interest is based on the posterior distribution using MCMC sampling technique (Gelman et al., 2004).

Therefore, the PGG EB model is a conjugate Poisson-Generalized Gamma model where the Poisson distribution represents the observed data likelihood and the Generalized Gamma (GG) distribution is used as the prior distribution of the Poisson parameter. As discussed in Vogelesang (1997), Hauer (1995), the Poisson distribution has become a standard for analysing accident data. However, the choice of prior for appropriate modelling differs and depends on the nature of the study. Thus, under PGG conjugacy, as highlighted in Mbata et al. (2018), the posterior density distribution is obtained as Equation (2):

$P\left(\tilde{\theta}_{i} \mid Y_{i} ; \alpha, \beta, \lambda\right)=\frac{\lambda \beta^{\alpha \lambda}}{\Gamma(\alpha)} \theta^{Y+\alpha \lambda-1} e^{-\left(E \theta+(\beta \theta)^{\lambda}\right)}, \alpha, \beta, \lambda, \theta>0$.

A proper posterior density distribution is obtained as

$p\left(\tilde{\theta}_{i} \mid Y_{i}, \alpha, \beta, \lambda\right)=\frac{\lambda \beta^{Y+\alpha \lambda}}{\Gamma\left(\alpha+\frac{Y}{\lambda}\right)} \theta^{Y+\alpha \lambda-1} e^{-(\beta \theta)^{\lambda}} . \alpha, \beta, \lambda, \theta>0$.

The PGG relative risk estimator, variance (Var) and standard deviation (SD) are obtained as

$\hat{\tilde{\theta}}_{i}^{P G G}=\frac{\Gamma\left(\alpha+\frac{Y_{i}+1}{\lambda}\right)}{\beta \Gamma\left(\alpha+\frac{Y_{i}}{\lambda}\right)}$.

$\operatorname{Var}\left(\hat{\tilde{\theta}}_{i}^{P G G}\right)=\frac{\Gamma\left(\alpha+\frac{Y_{i}}{\lambda}\right) \Gamma\left(\alpha+\frac{Y_{i}+2}{\lambda}\right)-\Gamma^{2}\left(\alpha+\frac{Y_{i}+1}{\lambda}\right)}{\beta^{2} \Gamma^{2}\left(\alpha+\frac{Y_{i}}{\lambda}\right)}$.

$S D\left(\hat{\tilde{\theta}}_{i}^{P G G}\right)=\sqrt{\operatorname{Var}\left(\hat{\tilde{\theta}}_{i}^{P G G}\right)}$

Where $\boldsymbol{Y}_{\boldsymbol{i}}$ be the observed number of fatal vehicular crashes in State $i(i=1, \ldots, K), \boldsymbol{E}_{\boldsymbol{i}}$ be the expected number of fatal vehicular crashes in State $i(i=1, \ldots, K), \boldsymbol{N}_{\boldsymbol{i}}$ be the total number of road vehicular crashes in State $i(i=1, \ldots, K), \boldsymbol{\theta}_{\boldsymbol{i}}$ be the maximum likelihood estimate of relative risk of fatality in State $i(i=1, \ldots, K), \widetilde{\boldsymbol{\theta}}_{\boldsymbol{i}}$ be the Posterior estimates of relative risk of fatality in State $i(i=1, \ldots, K)$. Hence, $\boldsymbol{E}_{\boldsymbol{i}}=\boldsymbol{N}_{\boldsymbol{i}} \overline{\boldsymbol{r}}=\boldsymbol{N}_{\boldsymbol{i}}\left(\frac{\sum_{i=1}^{k} \boldsymbol{Y}_{\boldsymbol{i}}}{\sum_{i=1}^{k} \boldsymbol{N}_{\boldsymbol{i}}}\right)$ while estimated $\boldsymbol{\theta}_{\boldsymbol{i}}$ is $\boldsymbol{\theta}_{i}=\frac{\boldsymbol{Y}_{\boldsymbol{i}}}{\boldsymbol{E}_{\boldsymbol{i}}}\left(\right.$ thus $\left.\boldsymbol{Y}_{i}=\boldsymbol{E}_{\boldsymbol{i}} \boldsymbol{\theta}_{\boldsymbol{i}}\right) . \overline{\boldsymbol{r}}$ is the overall road accident crashes risk in the entire States. The full derivation of PGG EB model and proof of some of its properties are found in Mbata et al. (2018).

2.1. The Special Case of PGG EB Model: is obtained by putting $\beta=1$ in Equation (3). Thus $p\left(\tilde{\theta}_{i} \mid Y_{i}, \alpha, 1, \lambda\right)=\frac{\lambda}{\Gamma\left(\alpha+\frac{Y}{\lambda}\right)} \theta^{Y+\alpha \lambda-1} e^{-(\theta)^{\lambda}} . \alpha, \lambda, \theta>0$.

The relative risk estimator, variance (Var) and standard deviation (SD) are derived as $\widehat{\tilde{\hat{\theta}}}_{i}^{P G G}=\frac{\Gamma\left(\alpha+\frac{Y_{i}+1}{\lambda}\right)}{\Gamma\left(\alpha+\frac{Y_{i}}{\lambda}\right)}$. 
$\operatorname{Var}\left(\hat{\tilde{\theta}}_{i}^{P G G}\right)=\frac{\Gamma\left(\alpha+\frac{Y_{i}}{\lambda}\right) \Gamma\left(\alpha+\frac{Y_{i}+2}{\lambda}\right)-\Gamma^{2}\left(\alpha+\frac{Y_{i}+1}{\lambda}\right)}{\Gamma^{2}\left(\alpha+\frac{Y_{i}}{\lambda}\right)}$.
$S D\left(\hat{\tilde{\theta}}_{i}^{P G G}\right)=\sqrt{\operatorname{Var}\left(\hat{\tilde{\theta}}_{i}^{P G G}\right)}$

To completely specify the posterior distribution model, the hyperparameter $\alpha$ of the prior distribution is estimated from the GG distribution using a method of moment estimation proposed by Huang and Hwang (2006). Given the pdf of GG distribution, when $\beta=1$, as

$p\left(\theta_{i} \mid \alpha, \lambda\right)=\frac{\lambda}{\Gamma(\alpha)} \theta^{\alpha \lambda-1} e^{-(\theta)^{\lambda}}, \theta>0$.

Thus, the rth Moment is expressed as

$E\left(\theta^{r}\right)=\mu^{r}=\frac{\Gamma\left(\alpha+\frac{r}{\lambda}\right)}{\Gamma(\alpha)}$

The mean and variance are expressed in Equation (13) and Equation. (15) as

$\mu=\frac{\Gamma\left(\alpha+\frac{1}{\lambda}\right)}{\Gamma(\alpha)}$

$\mu^{2}=\frac{1}{K} \frac{\Gamma\left(\alpha+\frac{2}{\lambda}\right)}{\Gamma(\alpha)}+\frac{(K-1)}{K} \frac{\Gamma^{2}\left(\alpha+\frac{1}{\lambda}\right)}{\Gamma^{2}(\alpha)}=\frac{\Gamma(\alpha) \Gamma\left(\alpha+\frac{2}{\lambda}\right)+(K-1) \Gamma^{2}\left(\alpha+\frac{1}{\lambda}\right)}{K \Gamma^{2}(\alpha)}$

$\sigma^{2}=\frac{\Gamma(\alpha) \Gamma\left(\alpha+\frac{2}{\lambda}\right)-\Gamma^{2}\left(\alpha+\frac{1}{\lambda}\right)}{\Gamma^{2}(\alpha)}$

Therefore, square of the coefficient of variation (CV) is obtained as

$\frac{\sigma^{2}}{\mu^{2}}=\frac{\kappa \Gamma(\alpha) \Gamma\left(\alpha+\frac{2}{\lambda}\right)-K \Gamma^{2}\left(\alpha+\frac{1}{\lambda}\right)}{\Gamma(\alpha) \Gamma\left(\alpha+\frac{2}{\lambda}\right)+(K-1) \Gamma^{2}\left(\alpha+\frac{1}{\lambda}\right)}$

[9], opined that when $\lambda=1.0$ gives a Gamma distribution and when $\lambda=2.0$ approximately gives a Generalized Normal distribution. To optimize $\lambda$, value 0.5 is assumed. Therefore, when $\lambda=0.5$ in Equation (16), we have;

$\frac{\sigma^{2}}{\mu^{2}}=\frac{\mathrm{K} \Gamma(\alpha) \Gamma(\alpha+4)-K \Gamma^{2}(\alpha+2)}{\Gamma(\alpha) \Gamma(\alpha+4)+(K-1) \Gamma^{2}(\alpha+2)}$.

Simplifying by completing the squares, we have;

$\hat{\alpha}=\left[6\left(\frac{\mu^{2}}{\sigma^{2}}-\frac{1}{K}\right)+\left(\frac{1}{2}+\frac{2}{K}-\frac{2 \mu^{2}}{\sigma^{2}}\right)^{2}\right]^{\frac{1}{2}}-\left(\frac{1}{2}+\frac{2}{K}-\frac{2 \mu^{2}}{\sigma^{2}}\right)$

According to Marshall (1991), $\mu$ and $\sigma^{2}$ are estimated as

$\hat{\mu}=\frac{\sum_{i=1}^{k} \theta_{i} E_{i}}{\sum_{i=1}^{k} E_{i}}$ and $\hat{\sigma}^{2}=S^{2}-\frac{\widehat{\mu}}{\frac{1}{K} \sum_{I=1}^{k} E_{i}}$, where $S^{2}=\frac{\sum_{i=1}^{k} E_{i}\left(\widehat{\theta}_{i}-\widehat{\mu}\right)^{2}}{\sum_{i=1}^{k} E_{i}}$.

Monte Carlo error (MCE) and stationary dynamic trace plots are carried out to evaluate the accuracy and convergence of posterior estimates of the EB model. MCE estimates the difference between the mean of the sampled values and the true posterior mean value. As a rule of thumb, the simulation is run until the Monte Carlo error is less than about $5 \%$ of the sample standard deviation (Brooks and Gelman, 1998). For good details of Bayes theorem, see Gelman et al. (2004).

\section{Results}

The special case of PGG EB model is applied to reported road vehicular fatal accidents in Nigeria by states. The data were sourced from the National Bureau of Statistics (2013, 2014, 2015, 2017, 2018 and 2019), and the Nigerian states by geo-political zone aggregated data with the estimated expected counts are presented in Table 1. However, the 2016 data was excluded due to inconsistency in reporting with other years. The investigation is carried out using MCMC sampling technique by OpenBUGS statistical software and the program codes are found in the appendix. The posterior results of the EB model are presented in Table 2. The diagnostic dynamic trace plots are presented in Figure 1 for the six geo-political zones, respectively. The relative risk of fatal accident mapping is presented in Figures 2 and 3, respectively. 
Table 1: Nigerian States by Geo-Political Zone Aggregated Reported Road Vehicular Fatal Accidents (2013-2019)

\begin{tabular}{|c|c|c|c|}
\hline States & $\begin{array}{l}\text { Total Number of } \\
\text { Accidents (N) }\end{array}$ & $\begin{array}{l}\text { Observed Number of } \\
\text { Fatal Accidents (Y) }\end{array}$ & $\begin{array}{c}\text { Expected Number of Fatal } \\
\text { Accidents (E) }\end{array}$ \\
\hline Abia & 2526 & 750 & 1026.5819 \\
\hline Anambra & 2855 & 1132 & 1160.2896 \\
\hline Ebonyi & 4430 & 2505 & 1800.3793 \\
\hline Enugu & 5554 & 1782 & 2257.1798 \\
\hline Imo & 1405 & 569 & 571.0006 \\
\hline South-East (1) & 16770 & 6738 & 6815.4312 \\
\hline Akwa-lbom & 1036 & 444 & 421.0368 \\
\hline Bayelsa & 2831 & 1400 & 1150.5358 \\
\hline C/River & 2357 & 1105 & 957.8993 \\
\hline Delta & 1620 & 764 & 658.3780 \\
\hline Edo & 2965 & 1224 & 1204.9943 \\
\hline Rivers & 4997 & 2642 & 2030.8116 \\
\hline South-South (2) & 15806 & 7579 & 6423.6557 \\
\hline Ekiti & 833 & 274 & 338.5363 \\
\hline Lagos & 9885 & 3033 & 4017.3249 \\
\hline Ogun & 8784 & 4719 & 3569.8717 \\
\hline Ondo & 3209 & 1374 & 1304.1574 \\
\hline Osun & 3502 & 1769 & 1423.2344 \\
\hline Oyo & 3110 & 1467 & 1263.9231 \\
\hline South-West (3) & 29323 & 12636 & 11917.0477 \\
\hline Adamawa & 1326 & 418 & 538.8946 \\
\hline Bauchi & 2202 & 939 & 894.9064 \\
\hline Borno & 1336 & 703 & 542.9586 \\
\hline Gombe & 1857 & 724 & 754.6962 \\
\hline Taraba & 2319 & 957 & 942.4559 \\
\hline Yobe & 1568 & 784 & 637.2449 \\
\hline North-East (4) & 10608 & 4525 & 4311.1565 \\
\hline Benue & 2166 & 718 & 880.2757 \\
\hline FCT Abuja & 7005 & 1588 & 2846.8751 \\
\hline Kogi & 2156 & 816 & 876.2117 \\
\hline Kwara & 1834 & 782 & 745.3489 \\
\hline Nassarawa & 1984 & 546 & 806.3098 \\
\hline Niger & 3463 & 1305 & 1407.3845 \\
\hline Plateau & 2345 & 894 & 953.0224 \\
\hline North-Central (5) & 20953 & 6649 & 8515.4282 \\
\hline Jigawa & 1047 & 490 & 425.5072 \\
\hline Kaduna & 3574 & 1388 & 1452.4956 \\
\hline Kano & 4471 & 1822 & 1817.0419 \\
\hline Katsina & 1924 & 726 & 781.9254 \\
\hline Kebbi & 807 & 215 & 327.9698 \\
\hline Sokoto & 1578 & 683 & 641.3089 \\
\hline Zamfara & 1004 & 386 & 408.0318 \\
\hline North-West (6) & 14405 & 5710 & 5854.2807 \\
\hline Nigeria & 107865 & 43837 & 43837.0000 \\
\hline
\end{tabular}

Source: National Bureau of Statistics (2013, 2014, 2015, 2017, 2018 and 2019). 
Table 2: Nigerian States by Geo-Political Zone Relative Risk Estimates, Standard Deviation (SD), Monte Carlo Error (MCE) and Credible Interval of EB Model

\begin{tabular}{|c|c|c|c|c|c|c|}
\hline States & $\widehat{\widetilde{\boldsymbol{\theta}}}_{\mathbf{i}}^{\mathbf{P G G}}$ & SD & MCE & 5\%SD & $\begin{array}{c}\text { Lower Credible } \\
\text { Limit }\end{array}$ & $\begin{array}{c}\text { Upper Credible } \\
\text { Limit }\end{array}$ \\
\hline Ebonyi & $1.4120^{*}$ & 0.0281 & $6.08 \mathrm{E}-05$ & 0.0014 & 1.3580 & 1.4680 \\
\hline Imo & $1.0630^{*}$ & 0.0432 & $9.48 \mathrm{E}-05$ & 0.0022 & 0.9801 & 1.1490 \\
\hline Anambra & $1.0080^{*}$ & 0.0295 & $6.38 \mathrm{E}-05$ & 0.0015 & 0.9513 & 1.0670 \\
\hline Enugu & 0.8063 & 0.0188 & 4.09E-05 & 0.0009 & 0.7697 & 0.8436 \\
\hline Abia & 0.7676 & 0.0273 & $6.03 \mathrm{E}-05$ & 0.0014 & 0.7151 & 0.8221 \\
\hline South-East 1 & 0.9934 & 0.0121 & 2.51E-05 & 0.0006 & 0.9699 & 1.0170 \\
\hline Rivers & $1.3200^{*}$ & 0.0255 & $5.79 \mathrm{E}-05$ & 0.0013 & 1.2700 & 1.3700 \\
\hline Bayelsa & $1.2500^{*}$ & 0.0329 & $7.25 \mathrm{E}-05$ & 0.0016 & 1.1860 & 1.3150 \\
\hline Delta & $1.2180^{*}$ & 0.0430 & $9.40 \mathrm{E}-05$ & 0.0021 & 1.1350 & 1.3030 \\
\hline C/River & $1.1930^{*}$ & 0.0353 & $7.82 \mathrm{E}-05$ & 0.0018 & 1.1250 & 1.2630 \\
\hline Akwa-lbom & $1.1440^{\star}$ & 0.0522 & $1.18 \mathrm{E}-04$ & 0.0026 & 1.0440 & 1.2490 \\
\hline Edo & $1.0470^{*}$ & 0.0294 & $6.24 \mathrm{E}-05$ & 0.0015 & 0.9904 & 1.1060 \\
\hline South-South 2 & $1.1850 *$ & 0.0135 & 2.99E-05 & 0.0007 & 1.1580 & 1.2110 \\
\hline Ogun & $1.3320^{*}$ & 0.0193 & $4.23 \mathrm{E}-05$ & 0.0010 & 1.2950 & 1.3710 \\
\hline Osun & $1.2690^{*}$ & 0.0298 & $6.86 \mathrm{E}-05$ & 0.0015 & 1.2120 & 1.3280 \\
\hline Oyo & $1.1910^{\star}$ & 0.0307 & $6.70 \mathrm{E}-05$ & 0.0015 & 1.1310 & 1.2510 \\
\hline Ondo & $1.0830 *$ & 0.0288 & $6.35 \mathrm{E}-05$ & 0.0014 & 1.0270 & 1.1400 \\
\hline Ekiti & 0.9213 & 0.0522 & 1.19E-04 & 0.0026 & 0.8220 & 1.0260 \\
\hline Lagos & 0.7645 & 0.0138 & $3.15 \mathrm{E}-05$ & 0.0007 & 0.7377 & 0.7917 \\
\hline South-West 3 & $1.0630 *$ & 0.0094 & 2.13E-05 & 0.0005 & 1.0450 & 1.0820 \\
\hline Borno & $1.3640^{*}$ & 0.0501 & $1.11 \mathrm{E}-04$ & 0.0025 & 1.2680 & 1.4640 \\
\hline Yobe & $1.2900^{*}$ & 0.0451 & $1.07 \mathrm{E}-04$ & 0.0023 & 1.2030 & 1.3800 \\
\hline Bauchi & $1.0920^{\star}$ & 0.0350 & $7.80 \mathrm{E}-05$ & 0.0017 & 1.0240 & 1.1610 \\
\hline Taraba & $1.0560^{*}$ & 0.0335 & 7.34E-05 & 0.0017 & 0.9910 & 1.1220 \\
\hline Gombe & $1.0100^{*}$ & 0.0366 & $7.99 \mathrm{E}-05$ & 0.0018 & 0.9389 & 1.0820 \\
\hline Adamawa & 0.8460 & 0.0395 & 8.94E-05 & 0.0020 & 0.7701 & 0.9254 \\
\hline North-East 4 & $1.0570 *$ & 0.0157 & 3.50E-05 & 0.0008 & 1.0270 & 1.0880 \\
\hline Kwara & $1.1000^{*}$ & 0.0383 & $8.66 \mathrm{E}-05$ & 0.0019 & 1.0260 & 1.1760 \\
\hline Plateau & 0.9778 & 0.0320 & 7.20E-05 & 0.0016 & 0.9160 & 1.0410 \\
\hline Kogi & 0.9745 & 0.0334 & $7.50 \mathrm{E}-05$ & 0.0017 & 0.9102 & 1.0410 \\
\hline Niger & 0.9542 & 0.0261 & $5.54 \mathrm{E}-05$ & 0.0013 & 0.9037 & 1.0060 \\
\hline Benue & 0.8587 & 0.0312 & $6.96 \mathrm{E}-05$ & 0.0016 & 0.7987 & 0.9210 \\
\hline Nassarawa & 0.7243 & 0.0300 & $6.68 \mathrm{E}-05$ & 0.0015 & 0.6665 & 0.7842 \\
\hline FCT Abuja & 0.5711 & 0.0142 & $3.18 \mathrm{E}-05$ & 0.0007 & 0.5436 & 0.5993 \\
\hline North-Central 5 & 0.7846 & 0.0095 & 2.13E-05 & 0.0005 & 0.7660 & 0.8034 \\
\hline Jigawa & $1.2400^{*}$ & 0.0539 & $1.21 \mathrm{E}-04$ & 0.0027 & 1.1370 & 1.3480 \\
\hline Sokoto & $1.1240^{*}$ & 0.0417 & $8.94 \mathrm{E}-05$ & 0.0021 & 1.0440 & 1.2070 \\
\hline Zamfara & $1.0390^{*}$ & 0.0505 & $1.15 \mathrm{E}-04$ & 0.0025 & 0.9424 & 1.1400 \\
\hline Kano & $1.0240^{*}$ & 0.0237 & $5.52 \mathrm{E}-05$ & 0.0012 & 0.9779 & 1.0710 \\
\hline Kaduna & 0.9818 & 0.0259 & $6.10 \mathrm{E}-05$ & 0.0013 & 0.9317 & 1.0330 \\
\hline Katsina & 0.9769 & 0.0353 & 7.77E-05 & 0.0018 & 0.9089 & 1.0470 \\
\hline Kebbi & 0.7712 & 0.0486 & $1.09 \mathrm{E}-04$ & 0.0024 & 0.6788 & 0.8693 \\
\hline North-West 6 & 0.9808 & 0.0129 & 2.87E-05 & 0.0006 & 0.9557 & 1.0060 \\
\hline Nigeria & 1.0000 & & & & & \\
\hline
\end{tabular}

Note: *Asterisk implies Relative Risk (RR) $\geq 1$ (High Risk State). Non-asterisk implies Relative Risk (RR) < 1 (Low Risk State). SD (Standard Deviation), MCE (Monte Carlo error). 

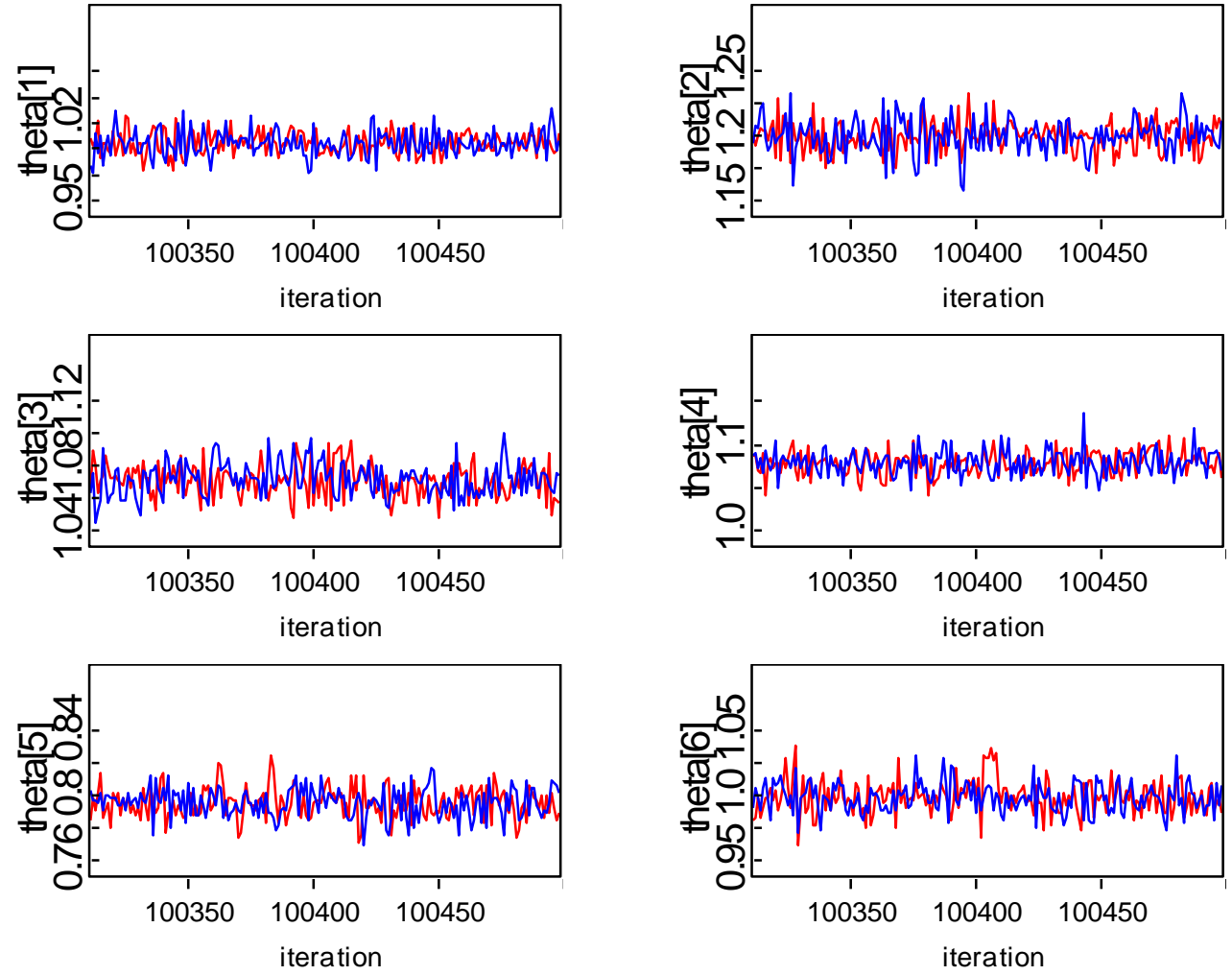

Figures 1: Dynamic Trace Plot of Posterior Convergence of the EB Model

Legend: Black = High Risk Area, White = Low Risk Area

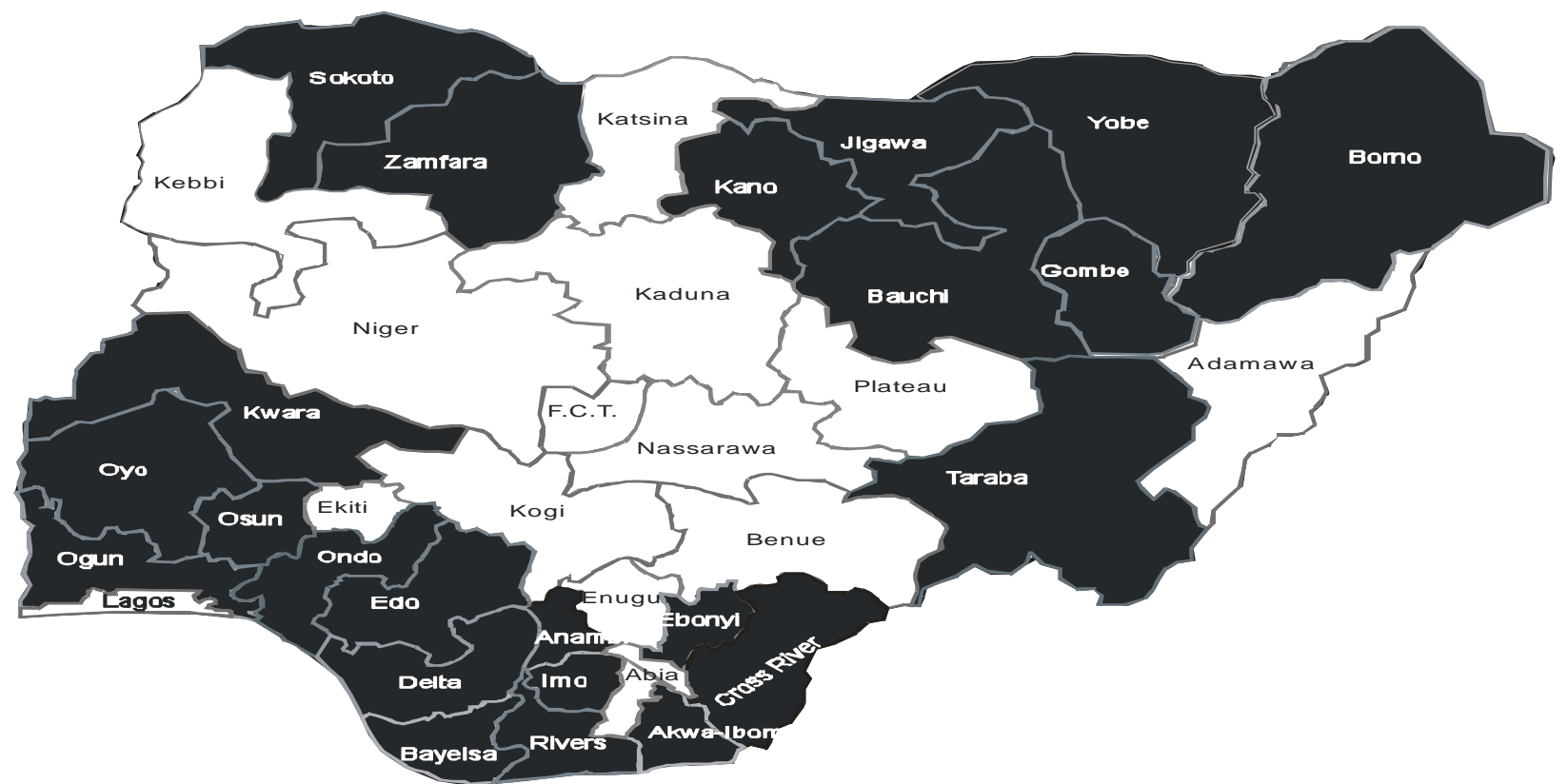

Figure 2: Nigeria States Relative Risk Estimates of Fatal Accident Incidence Mapping 


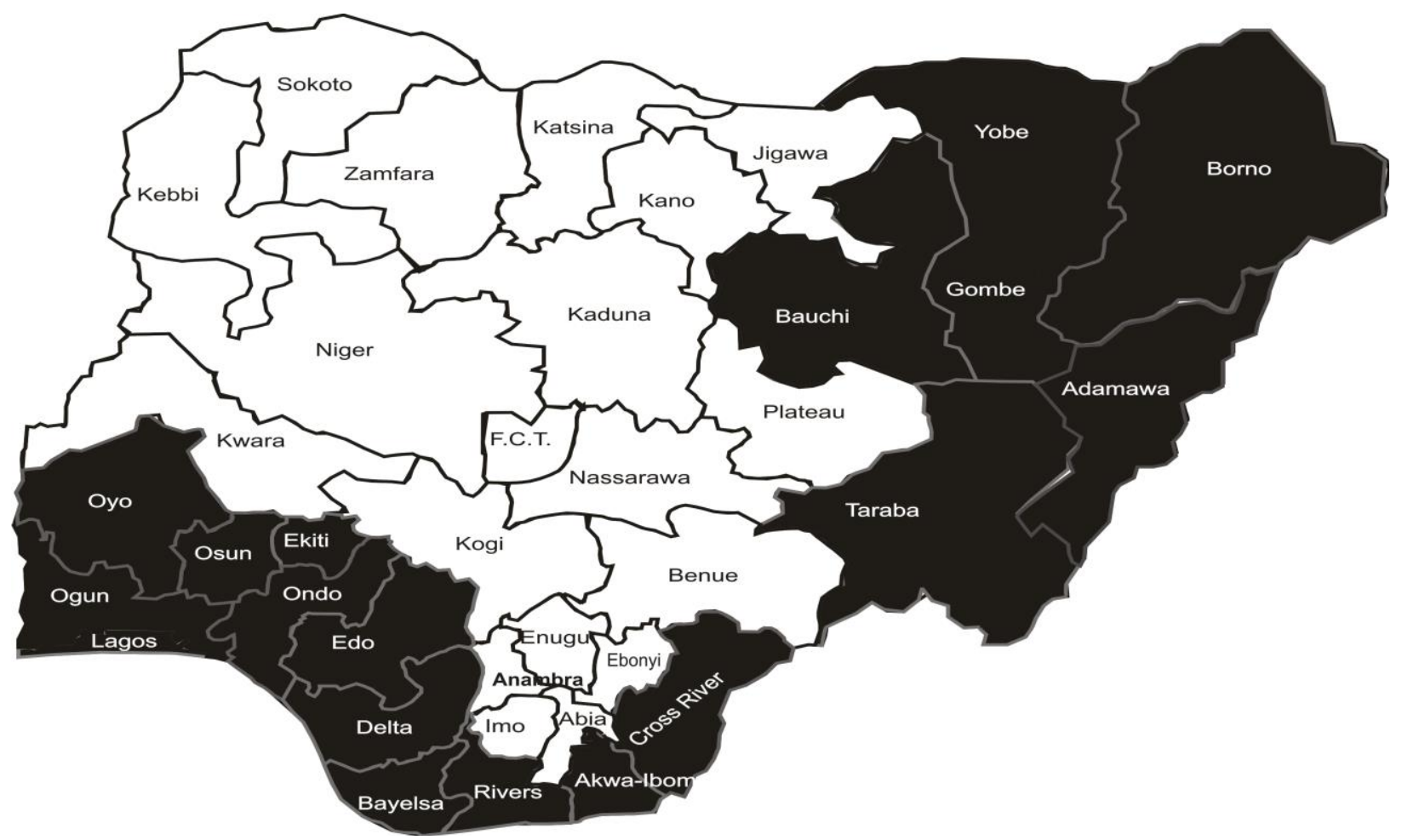

Figure 3: Nigerian States by Geo-Political Zone Relative Risk Estimates of Fatal Accident Incidence Mapping

\section{Discussion of Results}

The Nigerian states by geo-political zone aggregated reported road vehicular fatal accidents between 2013 and 2019 are presented in Table 1 with the corresponding total number of accidents and estimated expected fatal road accidents. The results from Table 2 indicate that the estimates of relative risk (RR) of road vehicular fatal accidents by state in Nigeria range from 0.5711 (FCT Abuja, the lowest) to 1.4120 (Ebonyi state, the highest). This implies that the risk of having a road vehicular fatal accident is highest in Ebonyi State and lowest in FCT Abuja. Meanwhile, RR $\geq 1$ implies higher risk while RR $<1$ implies lower risk. Therefore, the relative risk estimates of twenty-three (23) states (Ebonyi, Borno, Ogun, Rivers, Yobe, Osun, Bayelsa, Jigawa, Delta, Cross-River, Oyo, Akwa-Ibom, Sokoto, Kwara, Bauchi, Ondo, Imo, Taraba, Edo, Zamfara, Kano, Gombe and Anambra) indicate higher risk of road vehicular fatal accidents. While fourteen (14) states, including FCT Abuja (Kaduna, Plateau, Katsina, Kogi, Niger, Ekiti, Benue, Adamawa, Enugu, Kebbi, Abia, Lagos, Nassarawa and FCT Abuja), indicate a lower risk of road vehicular fatal accidents. The relative risk of road vehicular fatal accident mappings are depicted in Figures 2 and 3, respectively.

Studying the geo-political zones, the results indicate for South-East region that Ebonyi (1.4120), Imo (1.0630) and Anambra (1.0080) states have higher risk of road vehicular fatal accidents while Enugu (0.8063) and Abia (0.7676) states have a lower risk of road vehicular fatal accidents. The entire South-East region has a lower risk of road vehicular fatal accidents, estimated at 0.9934. For South-South region, all the states, Rivers (1.3200), Bayelsa (1.2500), Delta (1.2180), Cross-River (1.1930), Akwa-lbom (1.1440) and Edo (1.0470), are at higher risk of road vehicular fatal accidents, including the entire region at 1.1850. For SouthWest region, the risk of having a road vehicular fatal accident is higher in Ogun (1.3320), Osun (1.2690), Oyo (1.1910) and Ondo (1.0830) states than in Ekiti (0.9213) and Lagos (0.7645). The entire South-West region risk of a road vehicular fatal accident is higher at 1.0630 .

For North-East region, the risk of a road vehicular fatal accident is higher in Borno (1.3640), Yobe (1.2900), Bauchi (1.0920), Taraba (1.0560) and Gombe (1.0100) states than in Adamawa state (0.8460) respectively. The risk of a road vehicular fatal accident is higher in the entire North-East region at 1.0570. For North-Central region, Kwara state (1.1000) has a higher risk of road vehicular fatal accident while Plateau state (0.9778), Kogi state (0.9745), Niger state (0.9542), Benue state (0.8587), Nassarawa state (0.7243) and FCT Abuja (0.5711) have a lower risk of road vehicular fatal accidents. The entire North-Central zone has a lower risk of road vehicular fatal accidents, estimated at 0.7846. Finally, for the North-West region, Jigawa (1.2400), Sokoto (1.1240), Zamfara (1.0390) and Kano (1.0240) states have a higher risk of road vehicular fatal accidents while Kaduna 
(0.9818), Katsina (0.9769) and Kebbi (0.7712) states have a lower risk of road vehicular fatal accidents. The entire North-West result indicates a lower risk of road vehicular fatal accidents in the region, estimated at 0.9808 .

The results indicated that there is the accuracy of the posterior estimates of the EB model since $M C E<5 \% S D$ respectively. Consequently, the convergence of MCMC sampling as the chains overlap each other is shown in the stationary dynamic trace plots presented in Figure 1. Suggesting that the posterior estimates of the special case of PGG EB model is highly reliable.

\section{Conclusion}

The analyses have shown that South-East, North-Central and North-West regions have a lower risk of road vehicular fatal accidents while South-South, South-West and North-East regions have a higher risk of road vehicular fatal accidents. Therefore, it can be inferred that accidents in the South-East, North-Central and North-West are not usually fatal, though most major highways in the South-East are in poor condition, unlike in the North-Central and North-West regions where most highways are relatively in good condition. In addition, it was found that Ebonyi state has the highest risk of road vehicular fatal accidents in Nigeria because more than $50 \%$ of the crashes are fatal as a result of speed violation and poor condition of vehicles, as viewed by Ohakwe et al. (2011).

The high risk of road vehicular fatal accidents in the South-South and South-West can be attributed to high vehicular traffic density and over-speeding in most major highways in the regions, while North-East region is as a result of the poor condition of the major highways. Also, it can be deduced that the risk of road vehicular fatal accident in Lagos state and FCT Abuja is lower compared to Kano and Rivers states at higher risk of road vehicular fatal accident. Though Lagos state has a high vehicular density, the high traffic congestion in Lagos state and FCT Abuja alike is highly likely to reduce fatal crashes.

Finally, based on the results obtained in terms of geopolitical region, the risk of road vehicular fatal accident is highest in the South-South region with a relative risk estimate of 1.1850 while North-Central had the lowest risk of road vehicular fatal accidents with a relative risk estimate of 0.7846 . Generally, the major highways in Nigeria are highly vulnerable to fatal accidents due to the deplorable condition of the roads. This has been previously highlighted in Atubi (2010). The study is highly likely to aid planned government programs towards ameliorating and curbing vehicular road carnage in Nigeria. The study recommends comprehensive rehabilitation and reconstruction of major highways in Nigeria. The study has added to the body of literature the use of a special case of PGG model in analyzing and mapping accident data.

Acknowledgement: We thank the National Bureau of Statistics (NBS) for making the study data freely accessible available online.

Authors' Conflicts of interest: The authors declare that there are no conflicts of interest regarding the submission of this paper. Funding Statement: This research did not receive any specific grant from funding agencies in the public, commercial, or notfor-profit sectors.

\section{References}

[1] Afolabi, J. and Gbadamosi, K. (2017). Road traffic crashes in Nigeria: Causes and consequences. Transport \& Logistics: the International Journal, 17, 40-49.

[2] Atubi, A. O. (2010). Road Traffic Accident Variations in Lagos State, Nigeria: A Synopsis of Variance Spectra. Journal of African Research Review, 4, 197-218.

[3] Böhning, D., Dietz, E. and Schlattmann, P. (2000). Space-time mixture modelling of public health data. Stat Med, 19, $2333-2344$.

[4] Brooks, S. and Gelman, A. (1998). Alternative methods for monitoring convergence of iterative simulations, Journal of Computational and Graphical Statistics, 7, 434-455.

[5] Fawcetta, L., Thorpe, N., Matthews, J. and Kremer, K. (2017). A novel Bayesian hierarchical model for road safety hotspot prediction. Accident Analysis and Prevention, 99, 262-271.

[6] Gelman, A., Carlin, B., Stern S. and Rubin, D. (2004). Bayesian Data Analysis. Chapman and Hall/CRC, Boca Raton, Florida.

[7] Hauer, E. (1995). On exposure and accident rate. Traffic Engineering. Control, 36, 134-138.

[8] Huang, P. and Hwang, T. (2006). On new moment estimation of parameters of the Generalized Gamma distribution using it's characterization. Taiwanese Journal of Mathematics, 10, 1083-1093.

[9] Khodabin, M. and Ahmadabadi, A. (2010). Some properties of Generalized Gamma Distribution. Journal of Mathematical Sciences, 4, 9-28.

[10] Lee, A. S., Lin, W. Gill, G. S. and Cheng, W. (2019). An enhanced empirical Bayesian method for identifying road hotspots and predicting number of crashes. Journal of Transportation Safety \& Security, 11, 562-578.

[11] Marshall, R. J. (1991). Mapping Disease and Mortality rates Using Empirical Bayes Estimators. Journal of Applied Statistics, 40, $283-294$.

[12] Mbata, U., Okafor, R. and Adeleke, I. (2018). Poisson-Generalized Gamma Empirical Bayes Model for Disease Mapping. International Journal of Science and Technology, 7, 34-56.

[13] NBS (2019). Road Transport Data. National Bureau of Statistics (NBS), Abuja. https://nigerianstat.gov.ng/elibrary?queries[search]=Road\%20Transport\%20Data 
[14] Ohakwe, J., Iwueze, I., and Chikezie, D. (2011). Analysis of Road Traffic Accidents in Nigeria: A Case Study of Obinze/Nekede/lhiagwa Road in Imo State, Southwestern, Nigeria. Asian Journal of Applied Sciences, 4, 166-175.

[15] Okafor, R. O. and Mbata, U. A. (2012). A Bayesian Model for Inference on Population Proportions. WIREs Computational Statistics, $4,482-488$.

[16] Oyenuga, I. F., Ayoola, F. J., and Shittu O. I. (2016). Statistical Analysis of Pattern on Monthly Reported Road Accidents in Nigeria. Science Journal of Applied Mathematics and Statistics, 4, 119-128.

[17] Raudenbush, S. W. and Bryk, A. S. (1985). Empirical Bayes Meta-Analysis. Journal of Educational Statistics, 10, 75-98.

[18] Soro, W. and Wayoro, D. (2017). A Bayesian analysis of the impact of post-crash care on road mortality in Sub-Saharan African countries. IATSS Research, 41, 140-146.

[19] Uchenna, A., Chinedu, O., Pius, O., Olayinka, I, Nguku, P., Nsubuga, P., Ahmed, A., and Oyemakinde, A. (2019). Trends in road traffic accidents in Anambra State, South Eastern Nigeria: need for targeted sensitization on safe roads. The Pan African Medical Journal, $32(1): 12$. http://www.panafrican-med-journal.com/content/series/32/1/12/full

[20] Vogelesang, R. (1997). Empirical Bayes Methods in Road Safety Research. SWOV, Leidschendam, Netherland.

[21] WHO (2018). Global Status Report on Road Safety 2018. World Health Organisation (WHO), Geneva.

\section{Appendix}

\#OpenBUGS DATA APPLICATION CODES

\#PGG MODEL: alpha varies based on data estimate; beta is set at 1.0 while lambda is set at 0.5.

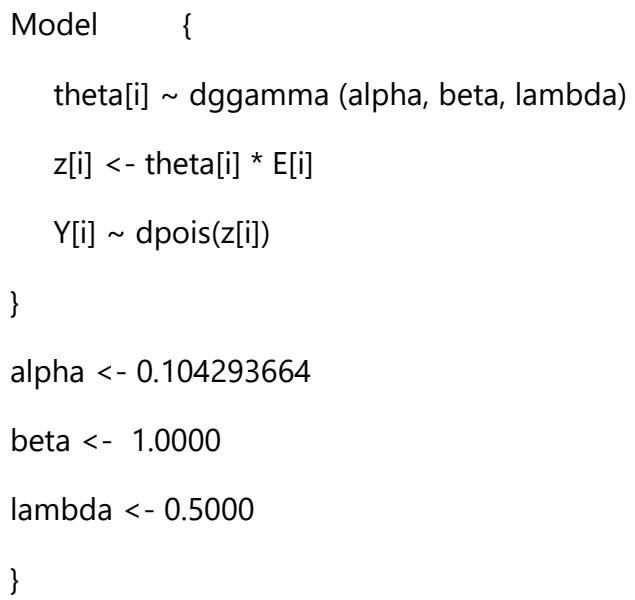

